\title{
Improving the quality of professional drivers' selection in haulage companies transporting minerals
}

\author{
Yuri Semenov ${ }^{1, *}$, Olga Semenova ${ }^{1}$, and Daniela Marasová ${ }^{2}$ \\ ${ }^{1}$ T.F. Gorbachev Kuzbass State Technical University, 650000 Kemerovo, 28 Vesennyaya St., Russian \\ Federation \\ ${ }^{2}$ Technical University of Košice, Faculty of Mining, Ecology, Process Control and Geotechnologies, \\ Letná 9, Košice, Slovakia
}

\begin{abstract}
The given article analyses the connection between drivers' psychophysiological parameters and road safety. Psychological methods were used to determine the psychophysiological features affecting the drivers' reliability. The parameters having the greatest impact on road safety include attention, memory, emotions, temperament, thinking, and stress resistance. To assess the professional qualities of drivers working on quarry transport in complex mining and road conditions it is highly recommended to use The Diagnostic\&Training Software Package Traffic Psychology. It includes the modules Attention, Emotions, Temperament, Memory, Assessment of Working Modes Influence upon the Operator's Activity and others. The authors present the research results and give instructions to use during the interview for selecting and recruiting drivers for Kuzbass coal enterprises and haulage companies transporting minerals. Keywords: the professional selection of drivers of technological transport for coal enterprises, drivers' testing, sensorimotor reactions, drivers' psychophysiological parameters
\end{abstract}

\section{Introduction}

Heavy trucks use for rock mass transportation on technological roads places special demands on professional training of drivers and their psychophysiological parameters. The peculiarity of road accidents involving quarry transport is the high costs of restoring the operability of both the transport unit and the elements of the technological infrastructure [12]. Such accidents often result in staff grave injuries and even deaths. The injured, the haulage companies and the authorities have to cover considerable costs of treatment and recovery while these means could have been used differently.

However, at the present stage of social development, quarry motor transport has no alternative due to its autonomy, mobility, and high-performance rate in practically any topographical, geological, and climatic conditions.

\footnotetext{
*Corresponding author: semenov63@mail.ru
} 
To reduce the number of accidents and the severity sets of actions are being developed that aim at quarry transport design perfection, an increase in active and passive safety. Great attention is paid to traffic management enhancement and improvement of traffic conditions in quarries. [3].

Drivers' selection and recruitment when scientifically grounded increase the operational reliability of the system Driver - Vehicle - Road - Environment. The selection and staffing problem is extremely acute in those companies where transport vehicles operate in complex conditions [3-5]. Quarry transport operation demands much of the drivers and necessitates that they enjoy good health and physical condition, high psychophysiological reliability, and quality vocational training.

One of the most complicated stages in identifying the staff suitability for operating quarry vehicles is to determine and assess drivers' psychophysiological parameters [6-11]. The methods applied during the procedure include making up questionnaires and surveying by these, using worksheets with test tables and heaps of specially designed equipment, however, the greater part of these methods are labour- and time-consuming.

Computer aids introduced into the process of selection and recruitment allow diminishing labour and time input and simplify the analysis of the results.

\section{The Research Method}

At the Motor Transport Department of Kuzbass State Technical University a new diagnostic \& training software package Traffic Psychology was developed (Fig. 1). The software product includes a test programme and a database and allows not only determining quarry transport drivers' psychophysiological parameters but also analyzing the collected data.

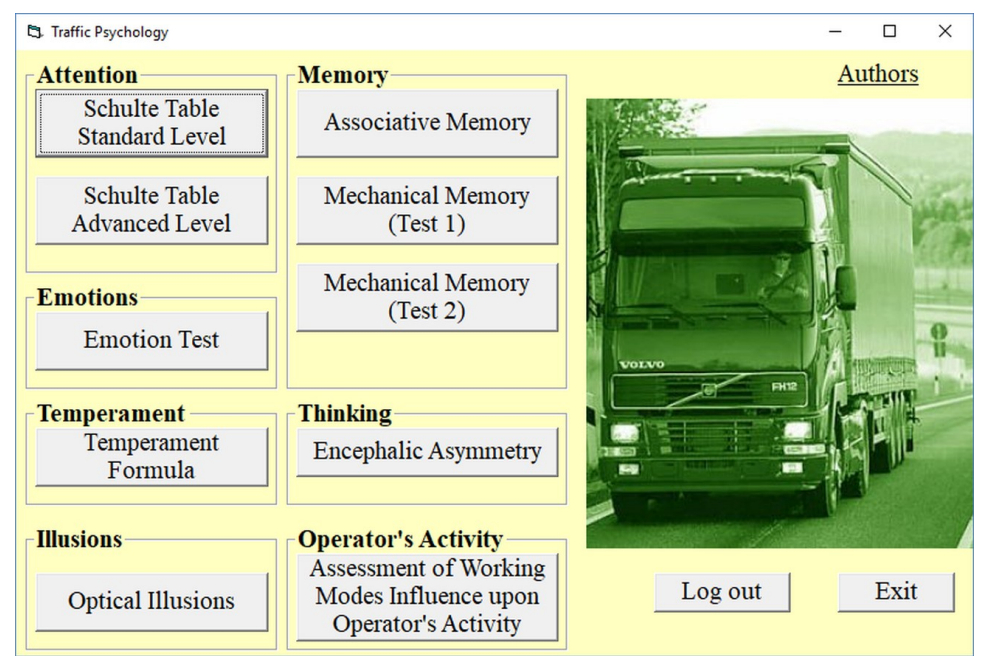

Fig. 1. Diagnostic\&Training Software Package Traffic Psychology.

The programme consists of ten specialized modules aimed at assessing drivers' attention, memory, emotions, temperament, thinking, and stress resistance. The module Attention uses automatically generated Schulte Tables. To imitate extreme conditions the table complexity was increased by adding distracting factors/noises (Fig. 2). The BassDarky Questionnaire is the basis for the module Emotions. The module Temperament allows assessing drivers' character traits based on the Eysenck Personality Questionnaire. The module Memory evaluates associative and mechanical memory. The evaluation of the first is based on the memorization and reproduction of logically related information, while 
the second evaluates the driver's ability to memorize and reproduce both numerical and textual information. The module Assessment of Working Modes Influence upon Operator's Activity allows assessing the driver's adaptability to working environment changes.

Research and evaluation of psychophysiological parameters using the given software package were carried out in the group of professional quarry transport drivers aged 24 to 52. Their parameters were determined and recorded from 9 a.m. to 11 a.m. since the highest working capacity is observed in the group during this period.

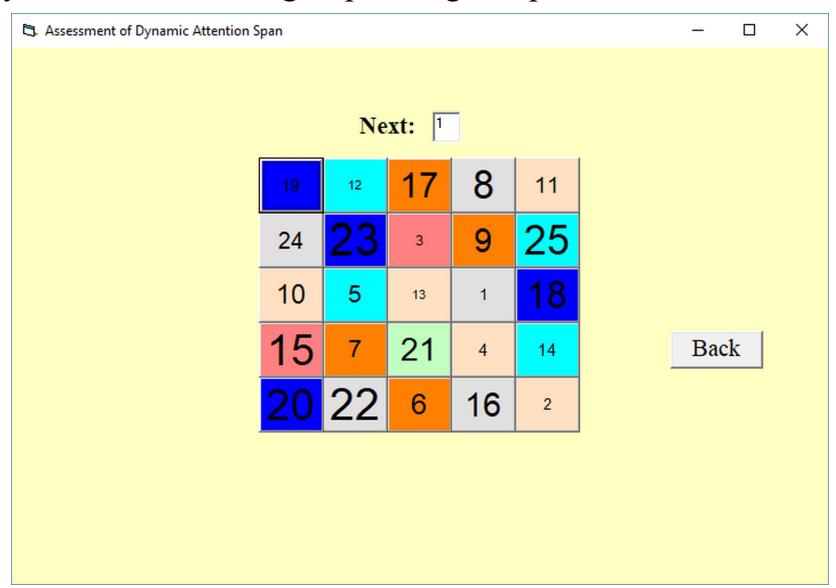

Fig. 2. Schulte Table Advanced Level.

\section{Results and Discussion}

The results of the research allow us to conclude that about $25 \%$ of the subjects demonstrate low attention index, especially in extreme conditions, which reveals insufficient concentration, lack of attention stability and slow switching (Fig. 3-4).

The drivers' age also affects attention parameters. The trend towards shortening attention span and lengthening the span for information processing was determined, which is especially characteristic of extreme working modes.

Time, sec

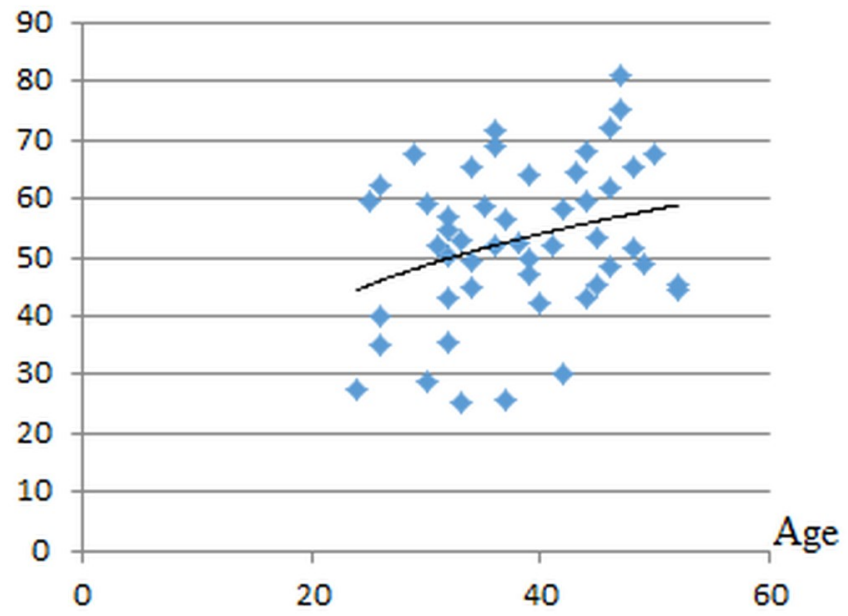

Fig. 3. Dependence of testing time on age (optimal working regime). 


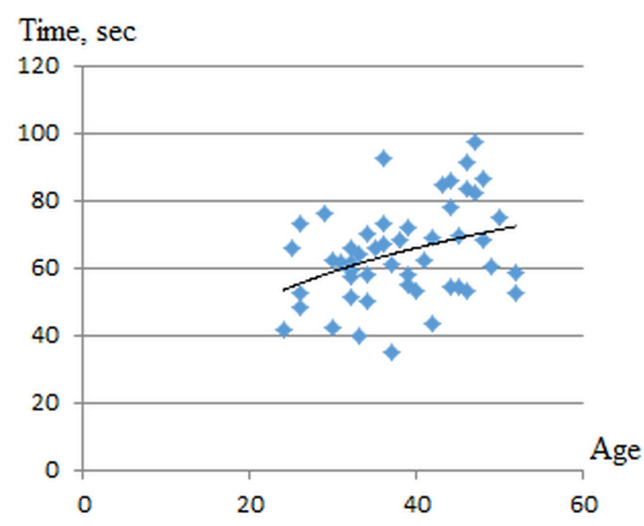

Fig. 4. Dependence of testing time on age (extreme working regime).

Research and evaluation of associative memory allowed concluding that it impairs after the age of 40 (Fig. 5). Above all, physiological changes in the human body and the deterioration of health, caused by professional activity, are responsible for this. However, mechanical memory parameters hardly change with age (Fig. 6). According to the results of the memory research, about $25 \%$ of the subjects have a low memory index. So these memory malfunctions are likely to produce a harmful effect on traffic safety.

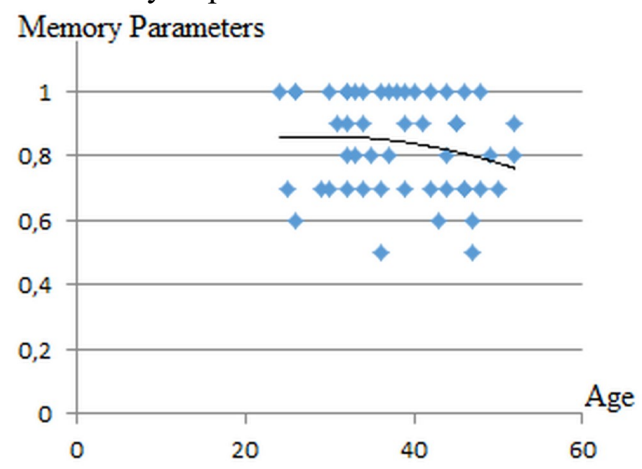

Fig. 5. Dependence of memory parameters on drivers' age (associative memory).

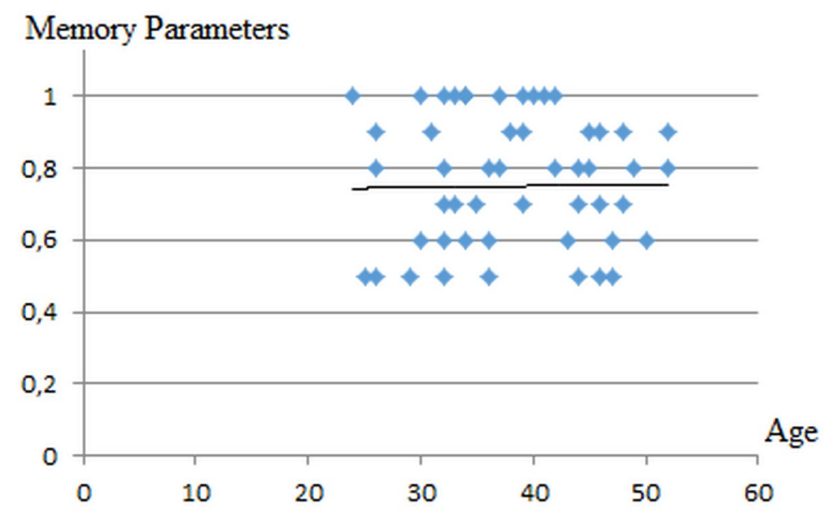

Fig. 6. Dependence of memory parameters on drivers' age (mechanical memory). 
The working modes influence upon operational activity was evaluated in optimal and extreme regimes. The optimal working regime implies a normal working environment, where the operator performs his functions automatically at a comfortable speed. In such conditions, the driver maintains a high working capacity for a long time due to a low level of psychological stress.

Testing a driver in the extreme working regime simulates driving a vehicle in complex road conditions and evaluates how accurate he is when driving if there is the poor state of the road pavement, road complex geometry, a lot of noises, etc. Analysis of the results displayed a faster decrease in working capacity than in the optimal regime.

The results of the research into how the working mode influences the operator's activity enabled concluding that about $25 \%$ of the subjects had the indices that do not meet the requirements for the position, and this concerns both the optimal and the extreme operational modes. With age, the tracking index of the subjects increases, which in turn negatively affects the perception and processing of information (Fig. 7).

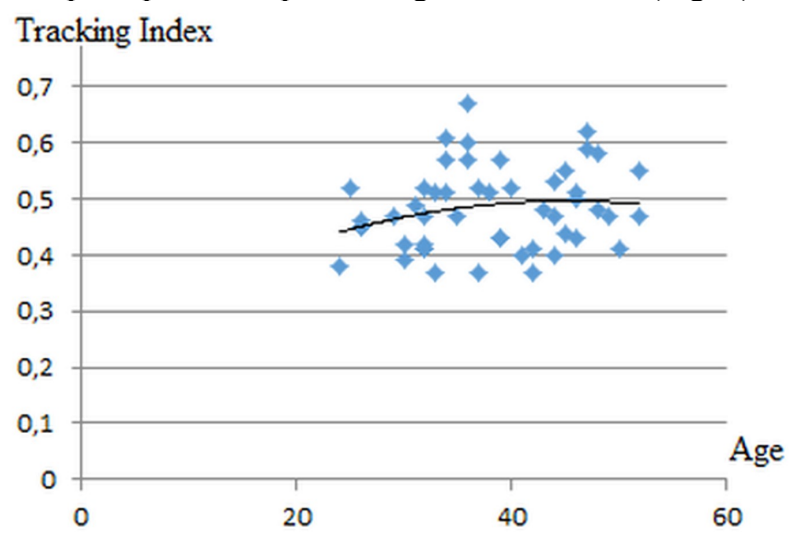

Fig. 7. Dependence of tracking index on age.

\section{Conclusion}

Professional selection and recruitment of drivers, a better quality of their training can considerably reduce the number of accidents on technological roads of Kuzbass coal enterprises and the severity of the accidents as well.

The Diagnostic\&Training Software Package Traffic Psychology allows testing the drivers at the recruitment stage. The programme modules enable evaluating psychophysiological parameters of the potential employees to hire for minerals transportation. Analysis of the applicant's attention, memory, emotions, temperament, thinking, stress resistance will produce a conclusion about the possibility of employment.

After the five-year use of the software the following conclusions were drawn: approximately $25 \%$ of the drivers do not qualify for the position because of their psychophysiological properties; certain properties, such as attention, sensorimotor reactions, associative memory tend to impair gradually; however, the drivers' mechanical memory does not seem to undergo significant changes with time. 


\section{References}

1. A. Parikh, A.M. Jain, International Journal of Engineering and Technical Research, 2:3, 86-89 (2014)

2. H. Frumkin, Urban sprawl and public health: Designing, planning, and building for healthy communities (Island Press, New York, 2004)

3. T. Carter, Fitness for Work, 22, 564 (2013)

4. F. Gérardin, Atmospheric Environment, 127, 46-54 (2016)

5. B.K. Borland, B. G. Funke, M. Chacko, Traffic management, 30, 112-117 (2014)

6. S. Linda, T. Rothengatter, Applied social psychology, 15:8, 234-241 (2017)

7. M. Ciceri, M. Rita, G. Franco, R.S. Feldman, Psicologia generale (DTRS, Paris, 2013)

8. D. Shinar, Traffic Psychology and Behaviour, 1:2, 137-160 (1998)

9. M. Power, T. Dalgleish, Cognition and emotion: From order to disorder (Psychology press, London, 2015)

10. E.A. Morris, J.A. Hirsch, Travel Behaviour and Society, 21, 98-104 (2015)

11. T.C. Lansdown, A.N. Stephens, H.G. Walker, Accident Analysis \& Prevention, 74, 360-367 (2015) 